\title{
Alterações microclimáticas em cultivo de café conilon arborizado com coqueiro-anão-verde ${ }^{1}$
}

\author{
Microclimatic alterations in a conilon coffee crop grown shaded by green \\ dwarf coconut trees
}

\author{
José Ricardo Macedo Pezzopane ${ }^{2 *}$, Mariclei Maurílio Simões Marsetti ${ }^{3}$ Wesley Ribeiro Ferrari ${ }^{4}$ e José Eduardo \\ Macedo Pezzopane ${ }^{5}$
}

\begin{abstract}
Resumo - Medições microclimáticas (radiação fotossinteticamente ativa - RFA, temperatura do ar, umidade relativa do ar e velocidade do vento) foram realizadas em cultivos de café Conilon (Coffea canephora Pierre) a pleno sol e arborizados com coqueiro-anão-verde (Cocus nucifera L.), no município de São Mateus, ES (1845' S; 40¹1' W; 70 metros), durante o período de outubro de 2008 a junho de 2009, com o objetivo de apresentar os efeitos do cultivo arborizado no microclima. Os resultados obtidos mostraram diferenças na transmissão da RFA dentro do sistema arborizado em comparação ao cultivo a pleno sol, com variações de 58 a $80 \%$ e 57 a $86 \%$ quando comparados dois episódios de amostragem. A transmissividade média da RFA provocada pelas plantas de coqueiro variou de 73 a $70 \%$ durante as duas épocas de amostragem. Com relação a velocidade do vento ocorreu uma redução média de $35 \%$ em sua incidência no cultivo arborizado. As diferenças na transmissão de radiação e na incidência de ventos proporcionaram diferentes regimes de temperatura do ar e umidade relativa do ar, com maior efeito sobre os valores diurnos e no ponto de amostragem situado na linha de coqueiros, onde a média da temperatura máxima foi até $1,7^{\circ} \mathrm{C}$ inferior ao cultivo a pleno sol.
\end{abstract}

Palavras-chave - Arborização. Microclima. Coffea canephora. Temperatura do ar. Radiação fotossinteticamente ativa.

\begin{abstract}
Microclimatic measurements (photosynthetically active radiation - PAR, temperature and relative humidity of air and wind speed) were made in a Conilon coffee crop (Coffea canephora Pierre), grown in two different conditions: shaded by dwarf green coconut trees (Cocus nucifera L.) and unshaded. The experiment was carried out at São Mateus, Espírito Santo State, Brazil ( $18^{\circ} 45^{\prime} \mathrm{S} ; 40^{\circ} 11^{\prime} \mathrm{W}$; 70 meters), between October 2008 and June 2009, aiming to show the effects of shading crop system into the microclimate. The obtained results had inside shown differences in the transmission of PAR in the shaded crop, with variations of 58 to $80 \%$ and 57 to $86 \%$ when compared the two episodes of sampling. The average transmission of PAR caused by green dwarf coconut trees varied of 73 to $70 \%$ during the episodes of sampling. The wind speed was reduced by $35 \%$ at the shaded crop. The differences in the transmission of PAR and the incidence of winds produced different values of temperature and relative humidity of the air with the greatest effect during day-light values period and at the sampling at coconut tree rows, where the average maximum temperature was up to $1.7^{\circ} \mathrm{C}$ lower than the unshaded ones.
\end{abstract}

Key words - Shaded. Microclimate. Coffea canephora. Air temperature. Photosynthetically active radiation.

\footnotetext{
*Autor para correspondência

${ }^{1}$ Recebido para publicação em 08/06/2010; aprovado em 08/04/2011

Projeto financiado pelo Conselho Nacional de Desenvolvimento Científico e Tecnológico/CNPq

${ }^{2}$ EMBRAPA Pecuária Sudeste, São Carlos-SP, Brasil, jricardo@cppse.embrapa.br

${ }^{3}$ Curso de Agronomia, CEUNES/UFES, São Mateus-ES, Brasil, maricleimarsetti@hotmail.com

${ }^{4}$ Curso de Agronomia, CEUNES/UFES, São Mateus-ES, Brasil, wesleyferrari22@hotmail.com

${ }^{5}$ Centro de Ciências Agrárias/UFES, Alegre-ES, Brasil, jemp@cca.ufes.br
} 


\section{Introdução}

A proposta de cultivos de cafeeiros arborizados busca, por meio do sombreamento moderado, atenuar as ocorrências climáticas extremas e proporcionar maior sustentabilidade aos sistemas de produção de café (BEER et al., 1998; CARDOSO et al., 2001; CAMPANHA et al., 2004, VAAST et al., 2006). Eles proporcionam ainda a agregação de uma fonte de renda extra para os cafeicultores e melhor aproveitamento da mão-de-obra durante o ano, benefício de grande importância para a agricultura familiar.

Os cultivos de café da espécie Coffea canephora (café robusta ou Conilon), assim como o Coffea arabica (café arábica), nas regiões tropicais da África, de onde são originados, são tradicionalmente realizados sob sombras de florestas nativas, com árvores raleadas ou não, ou mesmo com árvores introduzidas para tal fim. No Brasil, o cultivo do café Conilon, a exemplo do ocorrido com a espécie C. arabica, é realizado predominantemente a pleno sol. Um dos motivos da baixa adoção de arborização em lavouras de café Conilon está relacionado com o fato desta espécie ser originada de uma região caracterizada por temperaturas elevadas e estação seca moderada a acentuada (FERRÃO et al., 2007), o que se entende por maior adaptação a rigores climáticos.

Vários autores observaram a variação de elementos meteorológicos em diversos tipos de cultivos de cafezais arborizados nas diferentes regiões produtoras do Brasil e em outros países (BARRADAS; FANJUL, 1986; CARAMORI et al., 1996; PEZZOPANE et al., 2003; PEZZOPANE et al., 2007). Esses trabalhos evidenciaram as grandes diferenças microclimáticas relacionadas à incidência da radiação solar, velocidade do vento, temperatura do ar e déficit de pressão de vapor entre os sistemas arborizados de produção de café e cultivos a pleno sol, sendo constatada uma variabilidade temporal e espacial nos cultivos arborizados e que suas diferenças em relação a um cultivo a pleno sol vão depender do tipo de copa da árvore utilizada e da densidade do sombreamento.

A previsão de aquecimento global emitido pelo Painel Intergovernamental de Mudanças Climáticas (IPCC, 2007) indica um aumento da temperatura e alteração no regime de chuvas das regiões tropicais. De acordo com Fazuoli et al. (2007) e Camargo (2010), o uso da arborização seria uma das técnicas de mitigação para os cenários de aquecimento global e seus efeitos na cafeicultura. Sob este aspecto, a arborização se mostra promissora inclusive para o café Conilon (FERRÃO et al., 2007). Contudo, se faz necessária a realização de estudos microclimáticos para quantificar o efeito dos diferentes tipos de arborização na atenuação do microclima.
O presente trabalho foi realizado com o objetivo de avaliar as condições microclimáticas em sistema de produção de café Conilon a pleno sol e arborizado com coqueiro-anão-verde no município de São Mateus, ES.

\section{Material e métodos}

O experimento foi realizado no período de outubro de 2008 a junho de 2009 em uma área comercial de produção de café conilon (Coffea canephora Pierre) de aproximadamente 6 hectares, em terreno plano, cultivada a pleno sol e arborizada com coqueiro-anão-verde (Cocus nucifera L.), no município de São Mateus, ES (1845' S; $40^{\circ} 11^{\prime} \mathrm{W} ; 70$ metros). O clima da região é tropical com inverno seco, do tipo Aw (Köppen), com precipitação de $1.212 \mathrm{~mm}$ e temperatura média anual de $23,8^{\circ} \mathrm{C}$.

No cultivo de café consorciado com coqueiroanão-verde, implantado em 2002, as plantas de café estão no espaçamento de 2,0 m entre linhas e 1,5 m entre plantas, e as plantas de coqueiro-anão-verde estão no espaçamento de $10 \times 10 \mathrm{~m}$, distribuídas no talhão de café (FIG. 1). Esta configuração apresenta uma população de aproximadamente 3.200 plantas de café/ha e 100 árvores de coqueiro-anão-verde/ha. As linhas de café foram plantadas no sentido noroeste-sudeste. Nesta orientação, as linhas também se encontravam no sentido perpendicular ao sentido predominante dos ventos, que é norte-nordeste na região.

Em área adjacente ao talhão de café arborizado existia um talhão de café cultivado em sistema a pleno sol (PS) na mesma condição de espaçamento e tratos culturais do cultivo arborizado, que serviu de padrão para comparação das medições realizadas na presente pesquisa. Nos dois cultivos os tratos culturais foram realizados de acordo com as orientações técnicas para a região.

Para facilitar a apresentação dos resultados e o entendimento do estudo realizado estabeleceram-se alguns termos próprios no cultivo arborizado para a apresentação dos dados que estão ilustrados na Figura 1. Cada linha de café entre dois renques de coqueiro foi assim nomeada: ARB Copa (Linha de café situada na linha de coqueiros); ARB 2,0 SO (Linha de café com distância de 2,0 m da linha de coqueiros voltada para o sentido cardeal sudoeste); ARB 4,0 SO (Linha de café com distância de 4,0 $\mathrm{m}$ da linha de coqueiros voltada para o sentido cardeal sudoeste); ARB 4,0 NE (Linha de café com distância de 4,0 $\mathrm{m}$ da linha de coqueiros voltada para o sentido cardeal nordeste); ARB 2,0 $\mathrm{NE}$ (Linha de café com distância de 2,0 $\mathrm{m}$ da linha de coqueiros voltada para o sentido cardeal nordeste).

Foram realizadas medidas de radiação fotossinteticamente ativa (RFA), em duas datas, 04/10/2008 e 12/02/2009, em condição ensolarada. No cultivo arborizado, 


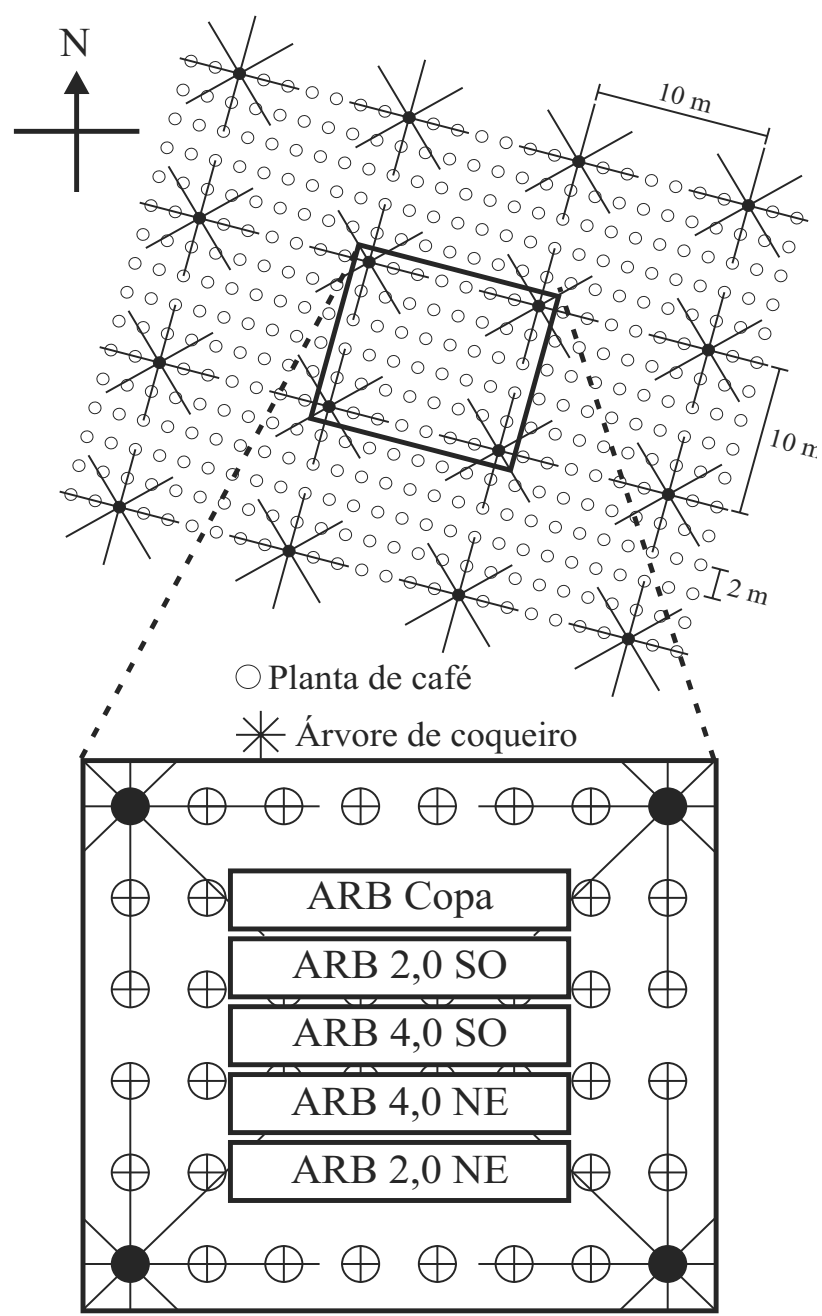

Figura 1 - Esquema ilustrativo do talhão de café arborizado com coqueiro-anão-verde (esquerda) e detalhe de uma parcela amostral evidenciando os cinco tratamentos utilizados para medidas microclimáticas

a amostragem da RFA foi realizada com um sensor linear de 1 $\mathrm{m}$ de comprimento (Licor Li-191) colocado horizontalmente sobre a copa dos cafeeiros, no sentido paralelo às linhas de plantas de café, efetuando-se uma medição instantânea, composta de dez leituras em trinta segundos. Para medir a RFA livre da interferência das plantas de coqueiro anão foi instalado um sensor em área externa ao experimento, cuja medição correspondeu a $100 \%$ de incidência.

As amostragens da RFA no cultivo arborizado foram realizadas sobre cada uma das cinco linhas de café entre dois renques de coqueiro (ARB Copa; ARB 2,0 SO; ARB 4,0 NE; ARB 4,0 NE e ARB 2,0 NE) em um total de quatro repetições dentro do talhão arborizado. Para compor a medida de cada parcela, mediu-se a RFA em três pontos situados no início, meio e final da parcela. As leituras foram realizadas no período da manhã (entre 9:30 e 10:30 h), ao meio dia (entre 11:30 e 12:30 h) e no período da tarde (entre 13:30 e 14:30 h) visando determinar a interceptação da RFA (relação entre a RFA sobre as plantas de café no cultivo arborizado e a RFA externa) ao longo do dia.

As medições microclimáticas consistiram também de coleta de dados de temperatura do ar, umidade relativa (Vaisala HMP50), instalados em abrigo multipratos, e velocidade do vento (MetOne 014A) realizadas de maneira contínua, entre os meses de dezembro de 2008 a julho de 2009, em dois pontos do sistema arborizado (ARB Copa e ARB 4,0 SO), além de um ponto do sistema pleno sol (PS), em área adjacente. Os sensores foram acoplados a um sistema automático de aquisição de dados (Campbell CR1000), programado para leituras a cada 20 segundos, médias a cada 15 minutos e a cada hora e obtenção dos valores médios e extremos diários.

Para complementar a discussão sobre a variação da umidade atmosférica, calculou-se a pressão de saturação e a pressão atual de vapor, visando à obtenção do déficit de pressão de vapor (diferença entre a pressão de saturação e a pressão atual de vapor).

Os dados da transmissividade da RFA no cultivo arborizado foram submetidos a uma análise de variância através do procedimento GLM do SAS (SAS, 2003), contemplando no modelo de análise os efeitos de época, tratamento e a interação época $x$ tratamento. Para a comparação múltipla de medias adotou-se a opção LSMEANS e o teste $\mathrm{t}$ ao nível de significância de 5\%. As médias dos dados diários dos elementos temperatura do ar (valores máximo, mínimo e médio) e do déficit de pressão de vapor foram submetidos ao teste t para médias com variâncias equivalentes, adotando-se o nível de $1 \%$ de significância, para detectar diferenças entre os pontos amostrais.

\section{Resultados e discussão}

Os resultados obtidos de transmissão da radiação RFA (TAB. 1) mostram que as plantas de coqueiro anão utilizadas no sistema de cultivo arborizado, promoveram uma atenuação na transmissividade da RFA até a altura das plantas de café (Q.M.R. $=21,50, \mathrm{~F}=18,81, \mathrm{p}<0,0001$ ), sendo que foram encontradas diferenças quando comparados os vários pontos amostrais dentro do sistema arborizado $(\mathrm{p}<0,0001)$. Não ocorreram diferenças estatísticas significativas na transmissividade entre as épocas de amostragem $(\mathrm{p}=0,0862)$ e interação entre épocas de amostragem e tratamentos $(\mathrm{p}=0,1039)$.

A variação da transmissividade da RFA nos diferentes pontos amostrais do cultivo arborizado está relacionada com a posição das plantas de café em relação aos coqueiros e o 
Tabela 1 - Transmissividade da RFA (relação entre a RFA sobre as plantas de café no cultivo arborizado e a RFA externa) em quatro tratamentos em um sistema de café arborizado com coqueiro-anão verde em São Mateus, ES, nos dias 04/10/2008 e 12/02/2009

\begin{tabular}{cccc}
\hline \multirow{2}{*}{ Posição } & \multicolumn{2}{c}{ Data de amostragem } & \multirow{2}{*}{ GERAL } \\
\cline { 2 - 3 } & $04 / 10 / 2008$ & Transmissividade da RFA & \\
\cline { 2 - 3 } & 58,5 & 57,3 & $57,9 \mathrm{C}$ \\
ARB Copa & 65,8 & 70,0 & $67,9 \mathrm{~B}$ \\
ARB 2,0 SO & 81,4 & 86,0 & $83,7 \mathrm{~A}$ \\
ARB 4,0 SO & 75,6 & 84,2 & $79,9 \mathrm{~A}$ \\
ARB 4,0 NE & 70,9 & 67,6 & $69,3 \mathrm{~B}$ \\
ARB 2,0 NE & 70,4 & 73,0 & \\
GERAL & & & \\
\hline
\end{tabular}

Médias seguidas da mesma letra maiúscula na coluna e da mesma letra minúscula na linha não diferem entre si pelo teste t $(\mathrm{p}>0,05 \%)$

movimento aparente do sol, fazendo com que a linha de café representada pela posição ARB COPA apresentasse o menor valor de transmissividade (média de 57,9\% considerando as duas amostragens), seguida pelas posições ARB 2,0 SO (67,9\%) e ARB 2,0 NE (69,3\%) que não diferiram entre si pelo teste t. Os pontos de amostragens ARB 4,0 NE e ARB 4,0 SO apresentaram as maiores médias de transmissividade (79,9 e $83,7 \%$, respectivamente), significativamente superiores aos demais pontos.

A descontinuidade de cobertura em sistemas arborizados causando diferenças nas transmissões em diferentes pontos do sistema também foi constatada por Farfan-Valencia et al. (2003), em sistemas arborizados de café na Colômbia e Pezzopane et al. (2005) em um sistema consorciado de cafeeiro com banana Prata Anã. Pezzopane et al. (2003), em análise microclimática de um cultivo de café arábica arborizado com coqueiro anão na região de Garça (SP), obtiveram transmissividade média de radiação solar de $58 \%$. As diferenças nos valores da transmissividade de radiação solar obtidos nesta pesquisa (71,7\% na média dos dois episódios) e o trabalho de Pezzopane et al. (2003) (58\%) podem ser atribuídas a densidade de coqueiros, que naquele trabalho era de 208 plantas ha-1, contra 100 plantas ha-1 nesta pesquisa.

Camargo e Pereira (1994), assim como DaMatta (2004), consideram que árvores de sombreamento em cultivos arborizados de café em regiões tropicais, como é o caso do estudo desta pesquisa, devem cobrir cerca de $20 \%$ da superfície, sendo que excessos de sombreamento podem ser prejudiciais à produção dos cafeeiros (PAULO et al., 2001; MORAIS et al., 2006). Diante disso é de se esperar que os cafeeiros situados nas ruas de coqueiros apresentem problemas em relação a produção de grãos, pois quando observadas as transmissões de radiação fotossinteticamente ativa nestas linhas (Tratamento ARB COPA - FIG. 2), verifica-se que sempre estão abaixo de $60 \%$.
Em todo o período de amostragem, a velocidade média diária do vento foi de $0,71 \mathrm{~m} \mathrm{~s}^{-1}$ no cultivo a pleno sol, e $0,47 \mathrm{~m} \mathrm{~s}^{-1}$ no cultivo arborizado (médias dos dois sensores) com redução média de $35 \%$ (FIG. 2). A máxima velocidade foi de $7,81 \mathrm{~m} \mathrm{~s}^{-1}$ na cultura a plano sol, no dia 04/01/2009. No mesmo dia, a velocidade máxima no cultivo arborizado foi de $5,4 \mathrm{~m} \mathrm{~s}^{-1}$. Para a cultura do café a redução da velocidade do vento promovida pela utilização de arborização é um dos efeitos mais benéficos desta prática (CAMARGO; PEREIRA, 1994; BEER et al., 1998).

Os maiores valores médios de temperatura máxima do ar ocorreram em ARB 4,0 SO (situado no centro da parcela arborizada) e no cultivo pleno sol, 33,4 e $32,9^{\circ} \mathrm{C}$ respectivamente (TAB. 2). As medidas realizadas em ARB COPA apresentaram os menores valores de temperatura máxima com média de $31,2^{\circ} \mathrm{C}$, diferindo-se, pelo teste $\mathrm{t}$, dos demais pontos de amostragem. Para a temperatura mínima, embora tenha ocorrido uma similaridade em relação ao comportamento da temperatura máxima, as diferenças entre tratamentos foram menos evidentes. Com relação à temperatura média o tratamento a pleno sol apresentou os maiores valores $\left(24,6^{\circ} \mathrm{C}\right)$, seguido pelos pontos de medidas ARB 4,0 SO e ARB COPA do cultivo arborizado (24,4 e $24,3{ }^{\circ} \mathrm{C}$, respectivamente), onde, assim como para a temperatura mínima, não foi encontrada diferenças estatísticas significativas entre as posições de leitura.

As diferenças nas transmissões de radiação que ocorreram no sistema arborizado (TAB. 1) proporcionaram diferentes regimes de temperatura do ar nos sistemas (FIG. 3). No ponto de amostragem de temperatura no centro da parcela (ARB 4,0 SO), onde ocorreram maiores transmissões de radiação fotossinteticamente ativa (TAB. 1), o regime médio de temperatura apresentou valores superiores em relação 

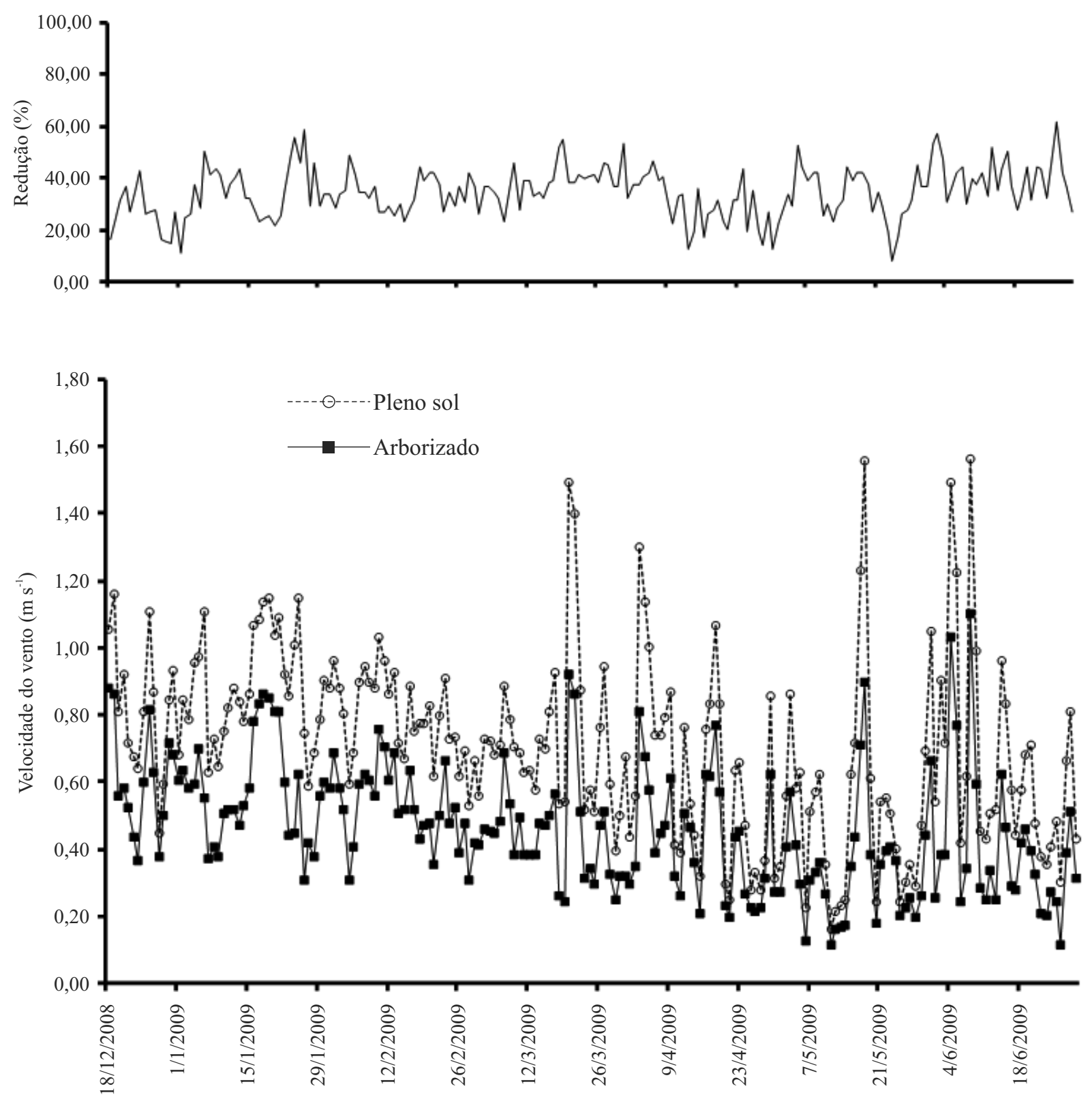

Figura 2 - Médias diárias de velocidade média do vento em cultivos de café a pleno sol e arborizado com coqueiro-anão-verde, em São Mateus, ES

ao ponto situado mais próximo das árvores de consórcio (ARB COPA) no período diurno, refletindo menores valores de máxima (TAB. 2).

O ponto de amostragem ARB 4,0 SO do cultivo consorciado e o cultivo a pleno SOL (PS) apresentaram comportamentos semelhantes nas horas mais quentes dos dias, porém com maiores valores de temperatura do ar no cultivo a pleno sol nas primeiras horas da manhã e no final da tarde.

O maior aquecimento do ar no ponto central do cultivo arborizado em relação ao cultivo a pleno sol, está associado à transmissividade superior a $80 \%$ nesse ponto em comparação com o cultivo a pleno sol e a menor movimentação do ar por efeito de quebra-vento promovido pela ação dos coqueiros (BRENNER, 1996; PEZZOPANE et al., 2007).

A variação diária da umidade relativa média do ar se mostrou inversa à temperatura do ar (FIG. 3). O déficit de saturação de vapor d'água apresentou diferenças mais distintas entre os pontos de leitura do que a umidade relativa do ar. No período entre 10-14 horas (TAB. 2), o déficit de saturação médio foi de $2,11 \mathrm{KPa}$ no ponto 
Tabela 2 - Médias diárias da temperatura do ar máxima (TMAX), mínima (TMIN) e média (TMED) $\left({ }^{\circ} \mathrm{C}\right)$ e déficit de pressão de vapor (DPV) $(\mathrm{kPa})$ em três períodos do dia, de dezembro de 2008 a junho de 2009, em cultivo de café a pleno sol (PS) e arborizado com coqueiro anão verde (ARB), em São Mateus, ES

\begin{tabular}{lcccccc}
\hline \multirow{2}{*}{ Variável } & \multirow{2}{*}{ PS } & \multicolumn{3}{c}{ ARB } & \multicolumn{3}{c}{ Valores de t } \\
\cline { 3 - 7 } & & ARB COPA & ARB 4,0 SO & A1 & B2 & C3 \\
\hline TMAX & 32,9 & 31,2 & 33,3 & $5,42^{* *}$ & $1,53^{\text {ns }}$ & $6,72^{* *}$ \\
TMIN & 19,5 & 19,5 & 19,2 & $0,09^{\text {ns }}$ & $1,27^{\text {ns }}$ & $1,37^{\text {ns }}$ \\
TMED & 24,6 & 24,3 & 24,4 & $1,47^{\text {ns }}$ & $1,03^{\text {ns }}$ & $0,43^{\text {ns }}$ \\
DPV 7-10 horas & 0,71 & 0,66 & 0,60 & $2,09^{*}$ & $5,27^{* *}$ & $3,21^{* *}$ \\
DPV 10-14 horas & 1,91 & 1,73 & 1,95 & $2,81^{* *}$ & $0,55^{\text {ns }}$ & $3,24^{* *}$ \\
DPV 14-18 horas & 1,50 & 1,35 & 1,45 & $2,28^{*}$ & $0,64^{\text {ns }}$ & $1,57^{\text {ns }}$ \\
\hline
\end{tabular}

${ }^{1}$ Comparação entre Pleno sol e ARB COPA; ${ }^{2}$ Comparação entre Pleno Sol e ARB 4,0 SO; ${ }^{3}$ Comparação entre ARB COPA e ARB 4,0 SO; ns: Não significativo; $* *$ Significativo ao nível de $1 \%$.
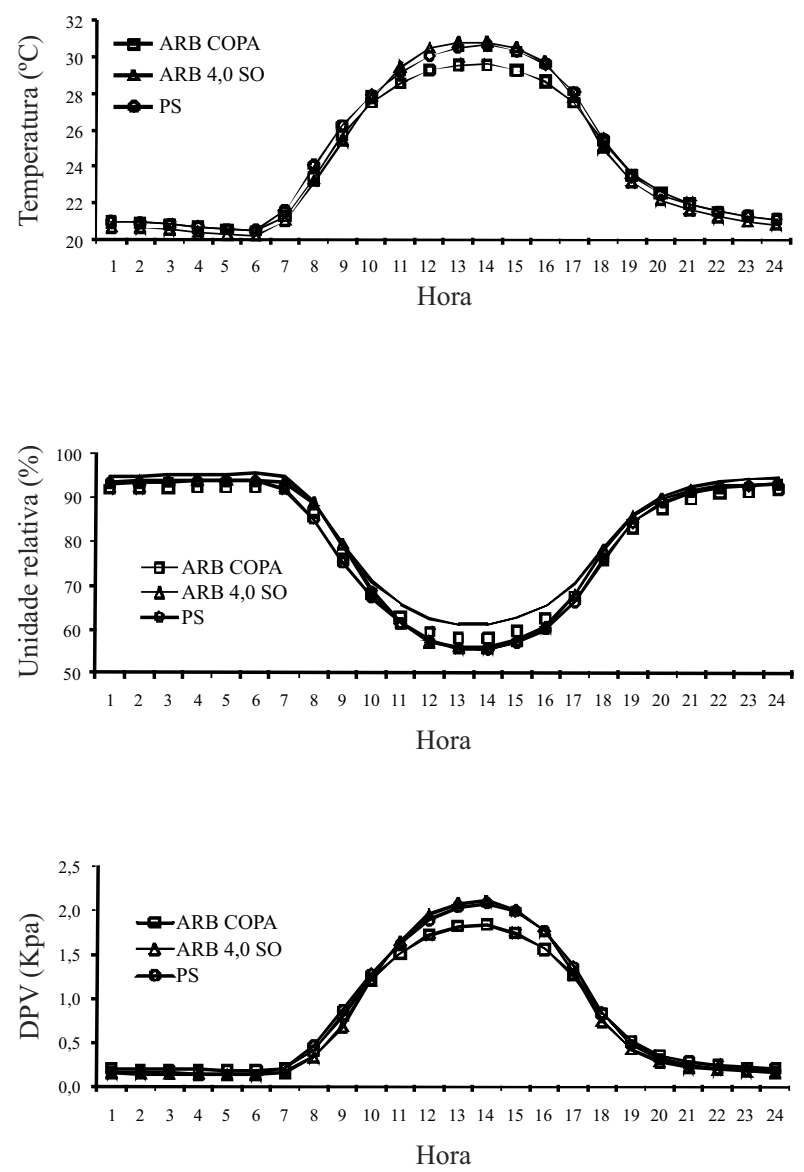

Figura 3 - Médias horárias da temperatura do ar, umidade relativa e déficit de pressão de vapor (DPV), de dezembro de 2008 a junho de 2009, em cultivo de café a pleno sol (PS) e em diferentes pontos amostrais de cultivo café arborizado (ARB) com coqueiro-anão-verde, em São Mateus, ES central do cultivo arborizado (ARB 4,0 SO), 2,09 KPa no cultivo a pleno sol e 1,84 KPa na posição de amostragem ARB COPA, que diferiu estatisticamente dos demais pontos. Observando a variação do déficit no período da manhã (7-10h) e a tarde (14-18 h), foram constatados maiores valores no cultivo a pleno sol (TAB. 2), com diferenças estatísticas para os pontos de leitura no cultivo arborizado no período da manhã e apenas para ARB 2,5 SO no período da tarde.

Menores valores de déficit de saturação de vapor em sistemas arborizados, como foi o caso da comparação entre PS e ARB COPA neste trabalho, também foram encontrados por Barradas e Fanjul (1986) e Pezzopane et al. (2007). Os autores atribuíram esses resultados aos menores valores de temperatura no período diurno, o que nessa pesquisa foi identificado principalmente no período da manhã, e também pela interceptação da radiação incidente sobre os cafeeiros arborizados, fato também verificado neste trabalho, principalmente no ponto de amostragem situado na linha dos coqueiros.

A associação do menor déficit de pressão de vapor, associado à diminuição da incidência de vento (FIG. 2) podem ter implicações na demanda hídrica das plantas de café no cultivo arborizado, sendo este um importante fator para períodos de déficit hídrico, característico das regiões produtoras de café Conilon no Espírito Santo (PEZZOPANE et al., 2010).

\section{Conclusão}

Nas condições em que foram conduzidas as medições microclimáticas, as árvores de coqueiro-anão-verde alteraram 
os padrões de incidência de radiação fotossinteticamente ativa sobre as plantas de café em sistema arborizado, sendo que a alteração variou em função da posição de medida dentro do sistema. O cultivo arborizado promoveu redução na incidência do vento na altura das copas dos cafeeiros e alterações no regime térmico e de umidade relativa do ar, com maior efeito sobre os valores diurnos e no ponto de amostragem próximo às arvores de coqueiro.

\section{Agradecimento}

Os autores agradecem ao Conselho Nacional de Desenvolvimento Científico e Tecnológico (CNPq) pela concessão de bolsa e auxílio financeiro.

\section{Referências}

BARRADAS, V. L.; FANJUL, L. Microclimatic characterization of shaded and open-grow coffee (Coffea arabica L.) plantations in Mexico. Agricultural and Forest Meteorology, v. 38, n. 1-3, p. 101-112, 1986.

BEER, J.; MUSCHLER, R.; KASS, D.; SOMARRIBA, E. Shade management in coffee and cacao plantations. Agroforestry Systems, v. 38, n. 1-3, p. 139-164, 1998.

BRENNER, A. J. Microclimatic modifications in agroforestry. In: ONG, C. K.; HUXLEY, P. (ed.). Tree-crop interactions - A physiological approach. Cambridge: University Press, 1996. Cap.5, p.159-188.

CAMARGO, M. B. P. de. The impact of climatic variability and climate change on arabic coffee crop in Brazil. Bragantia, v. 69 , n. 01 , p. $239-247,2010$

CAMARGO, A. P.; PEREIRA, A. R. Agrometeorology of the coffee crop. Geneva: World Meteorological Organization./ TD, n. 615, 43 p. 1994.

CAMPANHA, M. M. et al. Growth and yield of coffee plants in agroforestry and monoculture systems in Minas Gerais, Brazil. Agroforestry Systems, v. 63, n. 01, p. 75-82, 2004.

CARAMORI, P. H.; ANDROCIOLI FILHO, A.; LEAL, A. C. Coffee shade with Mimosa scabrella Benth. for frost protection in southern Brazil. Agroforestry Systems, v. 33, n. 03, p. 205-214, 1996.

CARDOSO, I. M. et al. Continual learning for agroforestry system design: university, NGO and farmer partnership in Minas Gerais, Brasil. Agricultural Systems, v. 69, n. 03, p. 235-257, 2001.
DAMATTA, F. M. Ecophysiological constraints on the production of shaded and unshaded coffee: a review. Field Crops Research, v. 86, n. 02-03, p. 99-114, 2004.

FARFAN-VALENCIA， F.; ARIAS-HERNANDEZ， J.J.; RIANO-HERRERA, N.M. Deasarrollo de una metodologia para medir sombrio en sistemas agroflorestales com café. Cenicafé, v. 54, n. 01, p. 24-34, 2003.

FAZUOLI, L. C.; THOMAZIELlO, R. A.; CAMARGO, M. B. P. Aquecimento global, mudanças climáticas e a cafeicultura paulista. O Agronômico, v. 59, n. 01, p. 19-20, 2007.

FERRÃO, M. A. G. et al. Origem, dispersão geográfica, taxonomia e diversidade genética em Coffea canephora In: FERRÃO, R. G. et. al. (Ed.). Café Conilon. Vitória, ES: Incaper, 2007. Cap. 3, p. 65-91.

IPCC Climate change 2007: The physical science basis. Genebra: IPCC, 2007. 1.8 p. A report of Working Group I of the Intergovernmental Panel on Climate Change. Assessment Report, 4. Disponível em: $<$ http://www.ipcc.ch>. Acesso em: 01 out. 2009.

MORAIS, H. et al. Microclimatic characterization and productivity of coffee plants grown under shade of pigeon pea in Southern Brazil. Pesquisa agropecuária brasileira, v. 41, n. 05, p. 763-770, 2006.

PAULO, E. M. et al. Produtividade do café Apoatã em consórcio com leguminosas na região da Alta Paulista. Bragantia, v. 60, n. 03, p. 195-199, 2001.

PEZZOPANE, J. R. M., PEDRO JÚNIOR, M. J., GALLO, P. B. Caracterização microclimática em cultivo consorciado café/ coqueiro-anão verde. Revista Brasileira de Agrometeorologia, v. 11, n. 02, p. 293-302, 2003.

PEZZOPANE, J. R. M., PEDRO JÚNIOR, M. J., GALLO, P. B. Radiação solar e saldo de radiação em cultivo de café a pleno sol e consorciado com banana 'Prata Anã'. Bragantia, v. 64, p. n. 03, 485 - 497, 2005.

PEZZOPANE, J. R. M., PEDRO JÚNIOR, M. J., GALLO, P. B. Caracterização microclimática em cultivo consorciado café/banana. Revista Brasileira de Engenharia Agrícola e Ambiental (Online), v. 11, n. 03, p. 256-264, 2007.

PEZZOPANE, J. R. M. et al. Zoneamento de risco climático para a cultura do café Conilon no Estado do Espírito Santo. Revista Ciência Agronômica, v. 41, n. 03, p. 341-348, 2010.

SAS Institute Inc., System for Microsoft Windows, Release 9.1, Cary, NC, USA, 2003 - CD Room.

VAAST, P. et al. Fruit thinning and shade improve bean characteristics and beverage quality of coffee (Coffea arabica L.) under optimal conditions. Journal of the Science of Food and Agriculture, v. 86, n. 02, p. 197-204. 2006. 